\title{
Becoming better trainers for our learners
}

\section{Karen Esmonde-White ${ }^{1}$}

Accepted: 29 June 2021 / Published online: 10 July 2021

(C) Springer-Verlag GmbH Germany, part of Springer Nature 2021

From the vantage of my home office, I am able to see many types of Michigan birds who come to my bird feeder seeking sustenance. I see the solitary red-breasted woodpecker picking at suet. I see charms of goldfinches collectively eating nyjer seeds. Cardinals, bluebirds, chickadees, titmouses, and sparrows also find respite. Their presence has been a delightful opportunity for me and my daughter to learn about these birds and their role in our ecosystem. It is also a delight to see the differences in how she learns from how I learn, and it made me appreciate our different approaches to learning. This personal observation builds on years of experience in making technical presentations, teaching classes or labs, and being a learner. This personal experience also ties into a growing role for me-providing education on Raman spectroscopy and technology. My understanding of how people learn comes informally as a parent, educator, and student. However, a recent need for formalized training on Raman spectroscopy within my company brought about a realization that I needed to become a better trainer.

In 2019, I was asked to develop a standardized training program on Raman spectroscopy for my company Endress+Hauser. While I had taught individual classes within a semester, mentored research students, and given countless technical presentations, I have never had the opportunity to build a class or workshop from the ground-up. I knew that the workshop would replace the existing ad hoc approach to training colleagues. The workshop would need to address fundamental principles in Raman spectroscopy and instrumentation, applications, and sales and marketing aspects. Most importantly, the workshop would be first given for specialized colleagues within a local entity and they would then distill the training to their local group as needed. That placed additional constraints on the workshop content because others would need to present the content as well. I needed to build a workshop that did not require 20 years of experience in

Karen Esmonde-White

karen@esmonde-white.com

1 Kaiser Optical Systems Inc., 371 Parkland Plaza, Ann Arbor, MI 48103, USA
Raman spectroscopy to facilitate, be modular in nature so that the local group could tailor a local workshop to their needs, and effectively train colleagues without repeated sessions. The introductory workshop was quickly dubbed "Raman Boot Camp" because of its intense focus to quickly build new knowledge, skills, and attitude. To support the workshop development, I sought virtual and internal training on continuing education.

Continuing education for adults who have completed their formal education is often in the form of short, intensive workshops. As workshop trainers, or instructors, we are educators! It is a challenge for educators to appreciate the adult learner, who brings experience, wisdom, and pragmatic needs to the continuing education environment. It's even harder to harness that collective wisdom into an effective group learning environment. We help our learners build new skills, develop new attitudes, and increase knowledge. But we also know from personal experience and many studies that "death by PowerPoint" workshops or classes do not effectively teach adults. With that in mind, how can we create an environment so that adults can truly learn and use the new knowledge, skills, and attitude? And, how can we train the next generation of trainers who continually put the learner first and avoid the "death by PowerPoint" trap?

These important questions were tackled with aplomb during a recent "Training the Trainer" (T3) workshop at my company Endress+Hauser. The premise of this workshop is that "it is all about the learner." From there, we learned a framework of building a training program called ADDIE. ADDIE is an acronym for Analyzing needs, Designing learning objectives, Developing and Implementing the training program, and Evaluating if the training was successful (ADDIE) $[1,2]$. I attended this workshop in the summer of 2019 with several colleagues. My goal was to build new skills to help me develop an engaging, practical, and useful "Raman Boot Camp" training workshop. Expecting a "death by PowerPoint" workshop, I was not prepared for preworkshop, workshop, and post-workshop activities. I had homework and quizzes, even before I stepped foot into the workshop! The workshop format and many types of activities continued to surprise me and reinforce that this was not a typical learning environment. We had presentations, small group learning, 
discussions, and practical exercises. All attendees also gave a 5min training introduction on a topic of their choice. I never had so much fun doing so much work for a training workshop.

After my T3 training workshop, we were expected to quickly use our newly forged knowledge, attitude, and skills to help with learning retention. Our post-workshop training was to apply the ADDIE cycle to our own training program whether it was a multi-day workshop or a short presentation. Putting those skills to work for Raman Boot Camp, I first analyzed the needs of my Raman Boot Camp learners. They were technically savvy but did not have experience or knowledge in Raman spectroscopy. They needed to have a foundational education in the principles of spectroscopy, Raman spectroscopy, and the equipment technology. But they also needed to understand where the equipment is used, know how the technology fit into the existing suite of product offerings, and be comfortable holding an introductory 5-min conversation about Raman spectroscopy. In short, the Raman Boot Camp needed to build knowledge, skills, and attitude. From that analysis, I designed learning objectives of the Raman Boot Camp ranging from technology knowledge to conversational skills. Importantly, I communicated those learning objectives to the learners, so the learners (and their supervisors) knew what to expect ahead of the Boot Camp. I next developed and implemented the training program. I wanted to replicate that combination of delightful surprise and varying learning formats that I had experienced in T3 for my learners. Similar to the format of my T3 training, I developed pre-training, training, and posttraining work for the Raman Boot Camp. I introduced concepts in spectroscopy through fun videos for the pre-training work. For the Raman Boot Camp training itself, I involved multiple colleagues for presentations, incorporated small group discussions to balance presentations, co-developed a hands-on laboratory module, held regular knowledge check-ins in a group quiz format, and developed practice customer scenarios that attendees needed to work through and then "teach" to the class. I also gave my learners post-workshop homework! Post-training work involved making a 30-day action plan. The group came together 30 days after the training to share successes, give feedback, and share accountability for meeting the goals in a supportive environment. The implementation was fun and with surprisingly little stress.

The first Raman Boot Camp was held in February 2020. Evaluating the training plan involved receiving a formal evaluation, as well as asking for feedback during our post-training follow-up session. My learners' positive feedback was a reflection not only on the skills I learned in the training, but also to the many colleagues who helped provide a practical, engaging, and useful training workshop. The ADDIE cycle and techniques from the workshop helped tremendously as I developed the Raman Boot Camp. It was more work to build the Raman Boot Camp based on the ADDIE training principles than a typical PowerPointbased training session. And yet, it was tremendously satisfying because I now had a framework that allowed me to think creatively, empathize with the learner, and be confident that this would ultimately benefit the learner. I was also grateful that the ADDIE framework empowered me seek feedback while developing the training program. The Raman Boot Camp was not created in a vacuum, and I regularly asked for feedback from my colleagues, fellow presenters, and even my learners.

As we adapt to a new normal with virtual, hybrid, and inperson learning opportunities, my challenge is to think of how to apply the ADDIE cycle and my knowledge of continuing education to these environments. I tried directly translating some of the Boot Camp modules to a virtual environment, but I do not think that they were as impactful. I am undeterred from this apparent miss, as it is an opportunity to learn and build something better for my learners. It is my hope to continue Raman Boot Camp when in-person events are safe. After all, that is the goal of the "Training the Trainer" workshop — a shifted mindset of continuous improvement so that we become better trainers for our learners. I hope that sharing my story has piqued your interest in becoming a more effective trainer. I encourage you to look at concepts in ADDIE, flipped classrooms, and continuing education learning and put them into practice. You and your learners will benefit from an engaging learning experience!

\section{Declarations}

Conflict of interest The author declares no competing interests.

\section{References}

1. Kurt S (2017) ADDIE model: instructional design. In: Educ. Technol. https://educationaltechnology.net/the-addie-modelinstructional-design/. Accessed 8 Jun 2021.

2. Molenda M. In search of the elusive ADDIE model. Perform Improv. 2003;42:34-6. https://doi.org/10.1002/pfi.4930420508.

Publisher's note Springer Nature remains neutral with regard to jurisdictional claims in published maps and institutional affiliations.

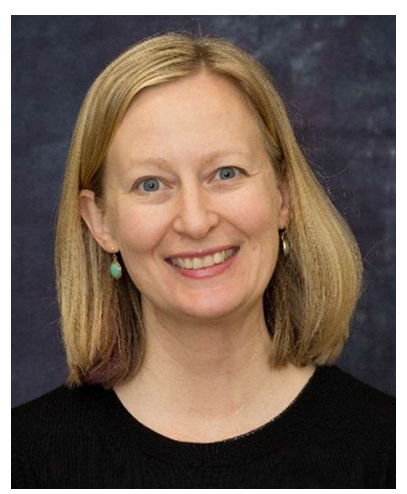

Karen Esmonde-White is the Food and Beverage Product Manager at Kaiser Optical Systems Inc. She completed her $\mathrm{Ph} . \mathrm{D}$. in biomedical engineering at the University of Michigan in 2009 and also holds a M.Eng. in pharmaceutical engineering and a M.S. and B.S. in chemistry. In addition to her work at Kaiser, she is an active volunteer for the SciX conference, Federation of Analytical Chemistry and Spectroscopy Societies, the Society for Applied Spectroscopy, and the Coblentz Society, and serves as a reviewer for spectroscopy, clinical and biomedical optics journals. 